\title{
Building Capacity to Promote STEAM in Communities - The impact of professional development for teachers, instructors and staff members - Work in Progress -
}

\section{Mr. Marcelo Caplan, Columbia College}

Marcelo Caplan - Associate Professor, Department of Science and Mathematics, Columbia College Chicago. In addition to my teaching responsibilities, I am involved in the outreach programs and activities of the department. I am the coordinator of three outreach programs 1) the NSF-ISE project "Scientists for Tomorrow" which goal is to promote Science Technology Engineering and Mathematics (STEM) learning in community centers in the Chicago area, 2) the Junior Research Scientists program funded by After School Matters of the city of Chicago, to promote STEM for high school students and 3) a collaboration with the Center for College Access and Success - Northeastern University to promote STEM learning in their Upward Bound Math \& Science program, also oriented for high school students. More information regarding the mentioned programs can be find at www.scientistsfortomorrow.org 


\section{Building Capacity to Promote STEAM in Communities The impact of Professional Development for teachers, instructors, and staff members (Work in Progress)}

"[Science] is more than a school subject, or the periodic table, or the properties of waves. It is an approach to the world, a critical way to understand and explore and engage with the world, and then have the capacity to change that world..."

— President Barack Obama, March 23, 2015

\section{1 - Introduction}

It is common knowledge that we are living in a time where accelerated changes in Science and technology have a significant impact on every aspect of our development and daily activities, whether in education, the workforce, leisure time, etc. This dynamic situation requires that the present and future workforce be prepared to adapt to rapid changes, as well as ready to lead these changes. To be able to get ahead of the changes, it is paramount that this workforce is literate, well prepared and skilled in Science, Technology, Engineering, Arts and Mathematics (STEAM) subjects, careers and skills.

Though the formal education system is in charge of preparing students towards this goal, it faces many limitations. Data also shows that students in the K-12 system spend less than 15 percent of their time in a supervised environment that fosters learning and exploration. Complementary to the work done in schools, Out-of-School-Time (OST) programs provided by community-based organizations (CBO) provide students with alternative environments for learning and growing. However, although these opportunities exist, only a small percentage of the student population participates in this informal frame, and many of the CBOs providing this possibility do not have the capability of implementing high-quality STEAM programming.

There are two main reasons for the CBOs not to develop STEAM programming. First, the STEAM programs are relatively expensive (in comparison with available resources and other potential OST activities), and second, the OSTs don't have qualified STEAM instructors available to implement high-quality STEAM programming in their centers.

One crucial question to address regarding qualified instructors is how well apprenticeship instructors, trained in a specific craft, would be interested and skilled in providing instruction at the CBOs' sites, upholding the quality of the program.

To address the need of the CBOs to have access to instructors literate and knowledgeable in contents and skills in STEAM subjects, the program "Scientists for Tomorrow" (SfT) from the Science and Mathematics Department - Columbia College Chicago developed the Professional Development series. These are professional development opportunities for instructors and staff members from CBOs interested in implementing STEAM programming in their centers. These 
Professional Development series (PDs) are designed following the Illinois Statewide Afterschool Quality Standards to ensure that the participants will be qualified to implement a sequential set of activities that promote STEAM in the youth they are serving.

Every year, for the past nine years, SfT provided multiple sets of two-day (16 contact hours each) PDs for potential instructors, staff members, resource coordinators, and administrators of $\mathrm{CBOs}$, as well as interested teachers. During the PDs, the participants are exposed to the content knowledge and pedagogical content knowledge of a module (e.g., Alternative Energies), and explore all the activities the youth will interact with during the implementation of the module. Anecdotic data collected after these PDs and activity logs provided by the instructors after each session they implemented in the field, contributed toward improving these PDs The data gathered supported the benefits of the PDs and the value the PDs bring to the community.

This goal of this paper is to answer these research questions: 1) Have the PDs implemented by Scientists for Tomorrow positively impacted module instructors' content knowledge and attitude toward STEAM-related subjects and careers? And 2) Are these PDs promoting professionals outside of typical STEAM professions to become competent STEAM instructors?

To answer these questions, participants in a PD took a Pre-Test and Post-Test content assessment and attitude survey. This paper discussed the results of these assessments from three complete sets of PDs that included more than 15 participants in each series.

\section{2 - Literature Review}

Many authors and public figures agreed providing STEM/STEAM education with competences and skills related to these fields is paramount for the future of society. These tools will facilitate the successful participation of future citizens in a competitive and changing labor market.

Many sources, including the National Science Board [1], concur that education in the STEMrelated fields is the vital importance for the economic development of our nation. Despite our historical record of achievement, the United States now lags behind other countries in these fields at the elementary and secondary levels [2], leading many potential STEM students not to embrace these fields. In November 2017, the Congressional Research Service [3] addressed the topic of a shortage (or a looming shortage) of scientists and engineers. They analyzed the effects of this shortfall in areas such as economic growth, job creation, the standard of living, and national security. Also, mentioning U.S. students lag those of other nations in STEM knowledge. These statements, with the inclusion of other factors, can lead to fewer and less talented U.S. scientists and engineers, a decrease in economic growth, and reduced economic competitiveness [4], [5]. Also, the United States government, understanding the problem of forming future citizens, put in place in 2013 a Five Years Strategic Plan to address this problematic [6]. 
Taking an in-depth look at the formal educational system, in particular, in large urban centers in the United States, the time and resources distribution did not promote the implementation of a strong curriculum in the area of STEAM. According to the National Center of Education Statistics [10], a $3^{\text {rd }}$ and $8^{\text {th }}$-grade student from public school receives the following hours per week of instruction per subject, presented in Table 1:

Table 1 - Hours per week of instruction per subject

\begin{tabular}{|l|c|c|c|c|}
\hline \multicolumn{1}{|c|}{ Subject } & \multicolumn{2}{c|}{ 3rd Grade } & \multicolumn{2}{c|}{ 8th grade } \\
\hline & Hours/week & $\%$ & Hours/week & $\%$ \\
\hline English, Reading or Language Arts & 9.9 & 30.2 & 6.5 & 19.4 \\
\hline Arithmetics or Mathematics & 5.8 & 17.6 & 5.0 & 14.8 \\
\hline Social Studies or History & 2.8 & 8.6 & 4.2 & 12.5 \\
\hline Science & 2.9 & 8.8 & 4.3 & 12.7 \\
\hline Physical Education & 1.7 & 5.1 & & \\
\hline Music & 1.0 & 2.9 & & \\
\hline Arts & 0.8 & 2.5 & & \\
\hline Recess & 1.8 & 5.5 & & \\
\hline
\end{tabular}

These systems are struggling to provide their students with the necessary skills. These efforts are centered primarily to promote students to achieve reading and writing in an acceptable grade level, and as secondary, the development of basic mathematics skills. Although STEAM fields are present in every curriculum, the facts presented in Table 2, show a lack of STEAM competencies in public schools in comparison with the nationwide, when Table 3 shows the low level of performance of the public schools in large urban settings. Table 2 and Table 3 data were taken from the National Report Card - National Center for Education Statistics (https://www.nationsreportcard.gov/). The percentage numbers placed on the table are the percentage of students at or above the National Assessment of Educational Progress (NAEP) proficient level

Table 2. Proficiency per subject and jurisdiction in the United States.

\begin{tabular}{|c|c|c|c|c|}
\hline Jurisdiction & Subject & 4 th grade & 8 th grade & 12 grade \\
\hline \multirow{3}{*}{$\begin{array}{l}\text { Public and Non- } \\
\text { Public Schools }\end{array}$} & Mathematics & 40 & 33 & 25 \\
\hline & Science & 38 & 34 & 22 \\
\hline & Technology and Engineering literacy & - & 46 & - \\
\hline \multirow{3}{*}{$\begin{array}{l}\text { Public Schools } \\
\text { only }\end{array}$} & Mathematics & 39 & 32 & 23 \\
\hline & Science & 37 & 33 & 21 \\
\hline & Technology and Engineering literacy & - & 45 & - \\
\hline \multirow{3}{*}{$\begin{array}{l}\text { Large Cities Public } \\
\text { Schools }\end{array}$} & Mathematics & 32 & 26 & - \\
\hline & Science & 20 & 19 & - \\
\hline & Technology and Engineering literacy & - & - & - \\
\hline \multirow{3}{*}{$\begin{array}{l}\text { Private Schools } \\
\text { only }\end{array}$} & Mathematics & - & - & - \\
\hline & Science & 48 & 43 & - \\
\hline & Technology and Engineering literacy & - & 60 & - \\
\hline
\end{tabular}


Table 3. Proficiency per subject in four large educational systems in the United States

\begin{tabular}{|l|l|c|c|c|}
\hline Jurisdiction & Subject & 4th grade & 8th grade & 12 grade \\
\hline \multirow{2}{*}{ Chicago } & Mathematics & 35 & 20 & \\
\cline { 2 - 5 } & Science & 12 & 7 & \\
\hline \multirow{2}{*}{ Pew York City } & Mathematics & 26 & 27 & \\
\cline { 2 - 5 } & Science & 18 & 13 & \\
\hline \multirow{2}{*}{ Los Angeles } & Mathematics & 15 & 20 & \\
\cline { 2 - 5 } & Science & 8 & 6 & \\
\cline { 2 - 5 } & Mathematics & 22 & 15 & \\
\cline { 2 - 5 } & Science & 12 & 10 & \\
\hline
\end{tabular}

Comparing the data presented in Table 1 and Table 2 makes it clear the low achievement levels in Science and Mathematics in the public school in general and on the four large school systems in the USA in particular. The demographics of these cities populations include in their vast majority: minorities (Afro-Americans and Hispanics), and low income. The data shows that the learning of Science and mathematics in these cities is not preparing future citizens to be part of a competitive workforce.

There is a need to provide these underserved urban populations an alternative path for their children to have access to equity to high-quality STEM/STEAM learning opportunities. There is a vast network of Out of School Time (OST) organizations to provide these services. These organizations offer a feasible alternative for those students to explore the STEAM fields outside of the frame of formal education. These organizations, through informal education settings, provide non-compelling free opportunities for students to investigate STEM/STEAM subjects in a non-threatening way. These OSTs are generally not for profit organizations whose vision, mission, and goals are oriented to support community members. If they are local organizations are typically called Community Based Organization - (CBO). These organizations serve noprivilege populations. To clarify, the term no-privilege population refers to groups that live in low-income areas and underserved by their educational systems. In the United States, there is a nationwide collaborative called STEM Ecosystems. As a definition, STEM learning ecosystems harness the contributions of educators, policymakers, families, businesses, informal science institutions, afterschool and summer providers, higher education, and many others towards a comprehensive vision of Science, Technology, Engineering, and Mathematics (STEM) learning for all children. The STEM Learning Ecosystems is composed of 84 local STEM Learning Ecosystems, that includes more than 1200 CBOs, and provide STEM academic enrichment to more than 33 million children K-12 [9, 11]

These organizations offer extracurricular activities before, after, or when the formal system is not in sessions - winter, spring, and summer breaks. These extracurricular activities provide a safe 
place for the children to be when their parents are working, and at the same time, children can learn and thrive in their education pursues.

From the information presented above, it is clear that to include STEM/STEAM learning experience into the formal system is expensive. In affluent neighborhoods, the local schools developed their network of OST activities open for all, but many of these services have an extra cost for the household. Wealthy parents have the financial capacity to support OST activities, in particular, OST STEM/STEAM oriented activities (e.g., Robotics, Science, and Engineering clubs). These activities are generally more expensive than Sports or Art clubs. Other parents from not affluent neighborhoods need to rely on the services provided by the CBOs.

According to the Wallace Foundation analysis of cost [8], there are three kinds of OST focus programs:

1) academic focus,

2) single non-academic focus (programs that specialize in an extracurricular area, such as theater, arts, etc.)

3) multiple focus (including both academic and non-academic activities).

STEM/STEAM activities follow into the academic focus. The report shows that the hourly cost per participant in an academic focus program is $100 \%$ more expensive than the hourly cost per participant in a multiple focus program.

Besides, STEM/STEAM academic enrichment programs, besides to be more expensive, required that their instructor will be knowledgeable in the area she/he is teaching. Ejiwale [16] shows that one of the reasons/barriers for the success of STEM/STEAM education in the formal system is the inadequate preparation and shortage in supply of qualified STEM teachers. This point made clear that finding qualified teachers for the formal educational system where they have a full stable position is a difficult task. Then finding qualified STEM/STEAM instructors that will be willing to participate in CBOs' academic activities is also a challenging task. The lack of qualified instructors is one of the primary reasons why many CBOs have few academic enrichment programs [17].

The optimal STEM/STEAM instructor to implement an OST activity need to have the following characteristics:

1) Be knowledgeable in the subject area (content knowledge),

2) Be knowledgeable in the ways to learn and teach in the informal setting (pedagogical content knowledge),

3) Time availability to provide instruction in the times the schools are not in session (generally afternoons, Saturdays and breaks),

4) The cost of the instruction needs to be affordable by the CBO. 
From the description above, it is clear that the potential poll of instructors able to provide highquality STEM/STEAM instruction in CBOs in their OST programs is very limited and expensive. Also, the cost of a high qualified STEM/STEAM instructor is higher than the cost of an average OST instructor.

One of the possible ways to provide CBOs with qualified STEM/STEAM instructors is to promote their own personal to become STEM/STEAM instructors. This personnel, for their current work in the CBOs, are familiar with the intricacies of the informal instruction and had incorporated in their core characteristics 2, 3, and 4 presented above[7]. Promoting staff members to become STEM/STEAM instructors will have multiple benefits for the CBO:

1) They will provide the centers with the instructors needed to provide high-quality STEM/STEAM education

2) They will increase the capacity of the $\mathrm{CBO}$ to be involved in relevant STEAM/STEAM neighborhood topics

3) It will ensure the sustainability of the STEM/STEAM programs in the CBOs.

Therefore, to successfully implement STEM/STEAM academic enrichment programs in the non-privileged neighborhood, Scientists for Tomorrow developed not only accessible programs for the local CBOS but also the local STEM/STEAM high-quality STEM/STEAM instructors.

\section{3 - Promoting staff/volunteer members to become STEM/STEAM instructors - Methodology}

\section{1 - Description}

To ensure the continuity of the academic enrichment programs in the CBOs, Scientists for Tomorrow developed a set of Professional Development (PD) series. This PD provides the Content Knowledge and Pedagogical Content Knowledge the local instructors needed to be able to implement the different academic modules in their local CBOs.

The goal of Scientists for Tomorrow Professional Development series is to ensure that the selected CBOs staff will able to implement the academic enrichment programs successfully. Many forces in the Education community did not believe that a person with a non-academic background in STEM/STEAM can be able to successfully serve as an instructor for STEM/STEAM programs and activities in informal settings. To this claim, it is clear that personal with previous knowledge in STEM/STEAM will better suit to serve in the role of STEM/STEAM leader, but what is the alternative when communities have not access to this well-prepared instructor? One of the many options CBOs are developing is the simplest one: not implementing STEM/STEAM programs. This decision only perpetuates the lack of equity and access to STEM/STEAM education for non-privileged neighborhoods. The absence of highquality STEM/STEAM education in non-privileged populations allows the growing gap in knowledge for their members. The gap in STEM skills can lead this non-privileged youth, not to 
be prepared to be a productive member living in the social environment of the fourth industrial revolution. In other words, it is the opinion of the author that not providing the mentioned youth high-quality STEM/STEAM education is not an option.

Therefore Scientists for Tomorrow took upon itself to provide the opportunity to the CBOs and its personal to receive a series of PDs that will provide them with the knowledge and tools needed to become STEM/STEAM instructors. In this way, the non-privileged youth and their families will have the opportunity to be introduced to the STEM/STEAM world and experiences. Then, they will be able to explore it and discover its potential. By having potential instructors ready to implement STEM/STEAM programs in their communities, the CBOs are one step closer to have the capability of implementing STEM/STEAM programming in their communities.

\section{2 - Profile of the staff/volunteer member of the CBO participating in the PD series}

It is essential to understand the profile of the staff/volunteer member of the CBOs that is participating in the process of becoming a potential STEM/STEAM instructor.

Based on the information collected over the years of implementing Scientists for Tomorrow is possible to say that, in general, the CBOs are trying to recruit current teachers from the neighborhood schools to serve as instructors for their OST programs. It is a sad fact that no so many teachers are participating in OST programs. Then, the few that decided to be instructors are not committed for an extended time. Also, many of the teachers committed to working in the CBOs are not necessarily Science or Mathematics teachers or have a substantial STEM/STEAM experience.

Another poll of potential instructors comes from students from local universities. These students, although they can be enrolled in a STEM career, they have limited experience in their subject as well as in working with youth in informal settings. Also, their availability is changing each semester, introducing another level of complexity in their scheduling. Many of these students are taking the role of an instructor as a potential source of income. In a positive note, anecdotal information provided for the CBOs mentioned that many of these students (especially those that have local roots in the communities) are working in the CBOs for more than two years. Also, a few continue working as a permanent staff member after their graduation.

The population presented above provides the vast majority of the potential instructors that participate in the PD series. For their lack of commitment, and continuous changes, this population of potential STEM/STEAM instructors is one of the potential problems in the development of the STEM/STEAM programs in the CBOs.

Therefore to ensure the continuity of the academic enrichment programs in the CBOs, especially in the non-privileged neighborhoods, Scientists for Tomorrow decided to provide at no cost for the CBOs, every year, a PD series to all the personal that the CBOs can recruit as a potential 
instructor. Through this resource, the CBOs can develop, "every time from scratch," a set of potential instructors to promote STEM/STEAM in their communities.

It is clear that although the PD series is free of charge for the CBOs, it has a cost for both Columbia College Chicago and the CBOs. The cost of the implementation of the PD series is the contribution of Columbia College Chicago. This cost includes instruction, materials, lunch, and refreshments. The CBOs are responsible for covering the salaries of the participants in the PD series.

\section{3 - The Implementation of the PD series}

Scientists for Tomorrow had developed a series of six STEM/STEAM modules: Alternative Energies, The Physics of Sound and Mathematics or Music, People and Plants, Introduction to Robotics, Robotics, and Underwater Robotics. These modules are designed to be implemented in 15 contact hours -10 meetings of 90 minutes each meeting once a week. Each module includes a set of 10 lesson plans, one for each meeting. Each lesson plan includes all the material the instructor needs to be able to:

a) Refresh the contents of the meeting

b) Prepare the materials and tools required for the implementation of the meeting

c) Detailed instructions for the construction assignments of the meeting

d) Leading questions for the development of the flow of the meeting

e) Proposed time table for the development of the activities of the meeting and the sequence

To complement the lesson plans, Scientists for Tomorrow developed a library of video tutorials for each module. The video tutorials serve as a refresher for the instructor. They included the Content Knowledge of a topic of the module. Also, the video tutorials serve as a guide to review the processes applied in the building of the module's artifacts. These video-tutorials are not a digital version of the instructor, just in case. These videos are supporting material for the nonexpert instructor to consult, review, and use then to prepare himself/herself before the class.

To facilitate the implementation of the OST academic enrichment program at the CBO, Scientists for Tomorrow provides to the CBOs a toolkit containing all the tools needed for the implementation of the given module and a set of disposable materials for the participants on the OST program. The toolkit is a loan from Columbia College Chicago, and the cost of the disposable materials is cover by the $\mathrm{CBO}$.

To ensure that the non-expert instructor will be ready to implement a module, this instructor "need" (it is not an option) to participate in the PD series of the module the instructor will teach in the $\mathrm{CBO}$ site. 


\section{4 - The Professional Development series}

Each content module, e.g., Alternative Energies, has been designed to be implemented in 15 contact hours. The Professional Development (PD) for each module has two PD meetings. These two meetings are taking place on Saturdays, on the campus of Columbia College Chicago. Each session has a duration of eight hours (generally from 9:00 am to 5:00 pm). The first meeting is taking place before the instructional process starts at the CBOs, and the second meeting four to six weeks later. In the first meeting, the PD centers on introducing the philosophy of informal learning. Then continues with the general content of the module and delves into the implementation of the lesson plans (generally from lesson plan \#1 to lesson plan \#4), allowing the instructors to develop the same projects and artifacts their future students will build under the instructor leadership.

The PD strategy is designed to provide the potential instructor not only the know-how of the material involved in the module but to reproduce a similar experience as their students will have. During the PD, the potential instructors will need to overcome the same challenges their students will have. They will learn from how to use the necessary tools for the given module and their safety procedures (e.g., multimeter, saw, solder iron, drill, and others), to make their design before building an artifact. Data collected from the participants in the PD corroborate that the experience of building the module's projects following the same process their students will do reduces their uncertainty and their anxiety. Many PD participants expressed that the implementation and practices through the "hands-on" parts of the training are what give them a clear picture of the content and also give them assurances that they can be in front of the group and lead the group successfully.

Another goal of the PD series is to generate a support team between the instructors. Because the majority of them are novices as STEM/STEAM instructors, the generation of a collaborative attitude between the potential instructors is essential for their success. Sharing experiences is one of the most important tools they can use to improve their teaching methodologies. A fundamental part of the second Saturday session is when the instructors share their teaching experiences, difficulties, and successes. If in the given group there are one or more instructors with more experience (e.g., instructors that are taking the PD for the second time after implementing successfully the given module one time), they will be asked to lead the discussion and provide feedback

After completing the second PD, the potential instructor has passed through the experience of learning the content and building all the projects. In the process, identify the points where their prospective students can need more assistance and prepare themselves to be effective when this such moment occurs.

Another safety net Scientist for Tomorrow built to ensure that the instructors are completing the module is that every instructor needs to submit an Activity Journal. This Activity Journal is an 
online tool designed to provide actual information about what is taking place on the site of the CBO. SfT team review the Activity Journals, and if needed, contact the instructor/site coordinator and discussed solutions to the given situation. It is crucial to ensure that the nonexpert novice instructor feels confident and supported.

For more anecdotic information about the Professional Development series, please watch the video following the link https://vimeo.com/142258458.

\section{4 - Evaluation of the Professional Development series}

While the success of the professional development can be assessed by the success of the participants in the OST academic enrichment programs [17], Scientists for Tomorrow designed an evaluation strategy for the Professional Development series. This evaluation is composed of three different instruments: 1) a general assessment of the PD session, 2) a Pre and Post STEM attitude survey, and 3) a Pre and Post content knowledge test. All the results of the instruments are anonymous. To match the Pre-Test and Post-Test, each participant used a personal code. These personal codes are not collected either stored.

The participants were aware from the start that the results of these assessments will not be shared with the CBOs. The participants completed the surveys and tests as a courtesy to the program organizers, knowing that the results of the evaluation have not any effect on their working relationship with the CBOs. The potential instructors had nothing to gain or to loose in connection with the score of the evaluation.

\section{1 - The Instruments}

Evaluation of the Professional Development series: The general evaluation of the PD session includes in addition to demographic information 11 statements assessed using a 1 to 5 Likert scale being 1 Strongly Disagree to 5 representing Strongly Agree, three close questions and three open questions.

Attitude towards STEM: The STEM attitude survey includes in addition to demographic information 19 statements assessed using a 1 to 5 Likert scale being 1 Strongly Disagree to 5 representing Strongly Agree. From these 19 statements, ten are positive, and nine are negative statements. All the statements (positive and negative) in the survey were assessed in a 1 to 5 Likert scale. After converting the negative assessments, the value of 5 represents a positive attitude towards the statement, and the value of 1 represents a negative attitude towards the statement

Content Knowledge: The content knowledge test follows the specific content of the module. 
In this manuscript will be presented results of the Professional Development of three different modules: Alternative Energies, The Physics of Sound and Mathematics of Music and Introduction to Robotics

The content knowledge test of the module Alternative Energies includes 21 multiple-choice questions. Each question has only one correct answer and three other distractors. The content knowledge test of the module The Physics of Sound and Mathematics of Music includes 20 multiple-choice questions. Each question has only one correct answer and three other distractors. The content knowledge test of the module Introduction to Robotics contains 17 multiple-choice questions. Each item has only one correct answer and three other distractors.

To asses, if there was a gain in Content Knowledge, a paired t-test was implemented comparing the Pre-Test and the Post-Test only of the participants that completed both.

The results of the surveys and content knowledge Pre and Post Tests taken in preparation for the start of the academic year 2018-2019 are below. All the Professional Development series were conducted by the same instructor, who is also the leading developer of the educational enrichment modules.

During this period, SfT implemented the Professional Development series for the six modules presented above $(n=152)$. Only the modules Alternative Energies $(n=37)$, Physics of Sound and Mathematics of Music $(n=17)$, and Introduction to Robotics $(n=22)$ have more than 15 participants that completed the Content Knowledge pre-test and post-test.

\section{2 - Results}

\subsection{1 -Evaluation of the Professional Development series.}

This evaluation includes ALL the participants in the Professional Development series of the six modules $(\mathrm{n}=152)$.

\subsubsection{1 - Demographics}

The age of the participants ranges between 18 years old to 63 years old, $51 \%$ male and $49 \%$ female, 57\% declared themselves Hispanic or Latino, 18.5\% Afro-American, $19.9 \%$ White and $4.6 \%$ Asian

\subsubsection{2 - Analysis of the statements.}

Table 4, presented below, shows the statement and the percentage of the participants that Agree and Strongly Agree with the statement. 
Table 4. Statements of the Evaluation survey and the percentage of the participants that Agree or Strongly Agree with the statements $(n=152)$

\begin{tabular}{|l|c|c|}
\hline \multicolumn{1}{|c|}{ Statement } & Agree & $\begin{array}{c}\text { Strongly } \\
\text { agree }\end{array}$ \\
\hline $\begin{array}{l}\text { 1. The instructor helped me understand the core ideas and } \\
\text { issues in this subject. }\end{array}$ & 9.2 & 88.2 \\
\hline $\begin{array}{l}\text { 2. The instructor explained what was expected of me when } \\
\text { implementing the module in the site }\end{array}$ & 9.2 & 86.2 \\
\hline $\begin{array}{l}\text { 3. The instructor encouraged critical, original, or creative } \\
\text { thinking. }\end{array}$ & 7.9 & 85.5 \\
\hline $\begin{array}{l}\text { 4. The instructor demonstrated interest in the participants' } \\
\text { learning }\end{array}$ & 9.9 & 86.2 \\
\hline \begin{tabular}{l} 
5. The instructor used the class time productively. \\
\hline $\begin{array}{l}\text { 6. The instructor created a welcoming and inclusive } \\
\text { classroom environment. }\end{array}$
\end{tabular} & 9.2 & 82.9 \\
\hline $\begin{array}{l}\text { 7. This PD helped me appreciate the significance of the } \\
\text { subject matter. }\end{array}$ & 8.6 & 86.2 \\
\hline $\begin{array}{l}\text { 8. The components of the PD, such as Introductory } \\
\text { explanations, group discussions, and hands-on activities, } \\
\text { were consistent with the goals of the PD }\end{array}$ & 10.5 & 85.5 \\
\hline $\begin{array}{l}\text { 9. The feedback I received during the PD was helpful. } \\
\text { 10. I felt comfortable asking questions during the PD }\end{array}$ & 11.2 & 8.9 \\
\hline $\begin{array}{l}\text { 11. This course helped me consider connections between } \\
\text { the PD material and other areas of my personal, academic, } \\
\text { or professional life. }\end{array}$ & 15.8 & 78.9 \\
\hline
\end{tabular}

When asked the question: "Compared to other PD I participated (not a part of the SfT PD series), the amount I learned in this PD was:" 66.4\% answer Much more, 23,7\% Somewhat more and $8.6 \%$ About the same. This affirmative answer is also reflected in the responses of the openended questions.

When asked the question: "Overall, the course was:" $71.1 \%$ answer Excellent and 25.7\%answer Very good.

\subsubsection{3 - Open-ended questions}

After reviewing the response of the open-ended questions, it is possible to see some patterns. These common constructs are presented below: 
To the question: "What elements of the PD most contributed to your learning?", the vast majority expressed that the use of hands-on activities to develop the concepts. Also, to construct the artifacts involved in each module was essential for their process of learning the materials. They declared that they gain the confidence needed to implement the module in their OST site.

Some of the participants' statements are below:

Receiving the content instructions with the hands-on activities was very helpful Trying to get a better understanding of what the kids need and how to explain it clearly Doing the experiments and activities myself as if I was the student.

The ability to make mistakes and have the assistance of fellow classmates along with instructor. To the question: "What improvements to the course would you recommend?", a large number of participants declared that they did not identify any aspect that required improvement ("none" was the most repeated statement). Another trend was complaining about lunch (the topic that we address accordingly). Many proposed to provide the PD series in more but shorter sessions. On the other hand, many participants asked for "more time for hands-on work."

Some of the participants' statements are below:

I wish we had more time. Many people were more skilled with aspects which made them finish sooner, which seemed to move the pace of the class for some that were more beginners.

Maybe a bit of a longer break. towards the end, I kinda was hitting a mental wall with learning Built in time for practice that wasn't connected to the completion of the project at hand. I wanted more time to practice.

The PD was very jam-packed. It may be helpful to have less content in each PD session. It would be helpful to have the instructors do mini-lessons to run through how we would teach so we can get live feedback from PD instructors.

To the last open question, "Do you have any other comments?" The common trend was that the experience was very positive, and many of the statements were self-reassurance that the participants could go to their communities and work in STEAM with their children in their communities.

Some of the participants' statements are below:

It was very fun, and helpful to participate in what the students will do before teaching. This will greatly help to anticipate issues that might come up when teaching students.

This is the 3 professional development I have taken and I enjoy every single one of them. The hands on is my favorite part.

I had a really great time. The instructor was fun and engaging and the hands on activities helped to prepare me to teach. 
SfT PDs are long but very effective. I always leaving feeling more confident teaching my students. Something differs from other PDs I attend- then tend to be shorter but much more dull and fail to provide any meaningful knowledge to take away.

From the information presented above, it is possible to conclude that the majority of the participants in the Professional Development Series have a positive experience. A point to remark is that they have the feeling that they can return to their communities and be part, as a STEM/STEAM instructor, in their CBOs OST academic enrichment programs.

\subsection{2 - Attitude towards STEM}

The comparison between the results of the Attitude towards STEM survey between the participants that completed the pre and post-survey $(n=76)$ shown no significant difference in the attitude towards STEM between the pre and post-survey. The mean of the pre-survey is $M=4.156$ when the mean of the post-survey is $\mathrm{M}=4.173$. This small difference can be the result that large part of the group that completed the pre and post-survey have a positive attitude towards STEM from the beginning, and that is one of the factors that potentially motivate them to complete the PD series and not quit after the first session (every series has two sessions on Saturdays of 8 contact hours each)

\subsection{3 - Content Knowledge Pre and Post Test}

For all the modules, the Pre Test was taken the first day of the Professional Development series before starting the PD, and the Post Test was taken after the second say and completing the PD It is important to remark that the Post Test was taken after eight hours of work on a Saturday, as the last task before finishing the day and leaving home.

\subsubsection{1 - Alternative Energies}

Results of the paired-samples t-test show that mean of the content knowledge test differs before the Professional Development $(\mathrm{M}=75.2, \mathrm{SD}=18)$ and after the $\mathrm{PD}(\mathrm{M}=81.2, \mathrm{SD}=14.9)$ at the .05 level of significance $(t=3.7, d f=36, n=37, p=0.0007<.05,95 \%)$ meaning that the intervention (PD) has a significant impact on the group. On average, Post Test was about 6 points higher than the Pre Test.

Below is a graph showing the relation between the Pre Test and Post Test per participant. The red line shows $($ Pre Test $=$ Post Test $)$. 


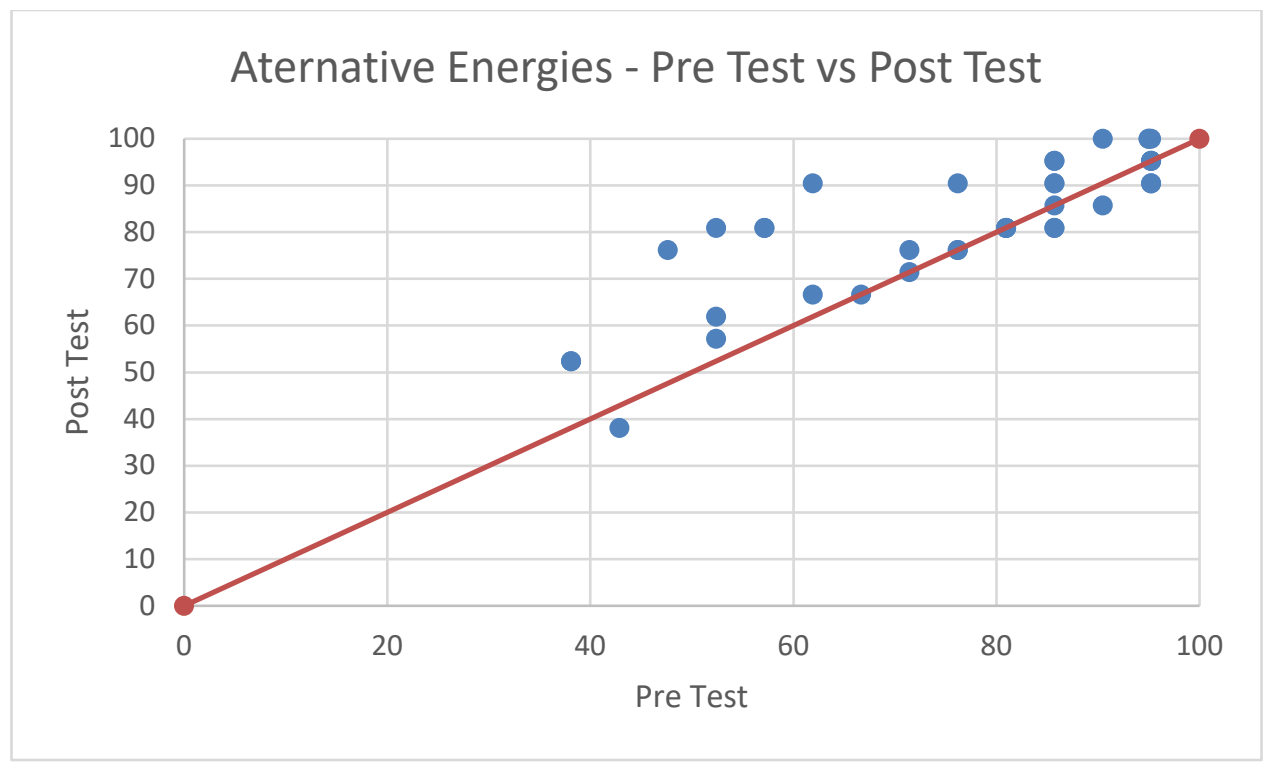

Figure 1. Alternative Energies $(n=37)$ - Content Knowledge Pre-Test versus Post-Test. The line in the graph represents score Pre-Test $=$ score Post-Test

The data collected shows that 20 of the participants that completed the Pre and Post-test $(\mathrm{n}=37)$ shows a Post-Test higher that the Pre-Test, 11 has the same score to the Pre and Post Test and 5 has a score lower than the Pre-test (the score of four of them was above 90, missing one question in the post-test).

\subsubsection{2 - The Physics of Sound and Mathematics of Music}

Results of the paired-samples t-test show that mean of the knowledge test differs before the Professional Development $(\mathrm{PD})(\mathrm{M}=46.4, \mathrm{SD}=22.1)$ and after the $\mathrm{PD}(\mathrm{M}=59, \mathrm{SD}=21.2)$ at the .01 level of significance $(\mathrm{t}=3.86, \mathrm{df}=16, \mathrm{n}=17, \mathrm{p}<.01,99 \%)$ meaning that the intervention (PD) has a significant impact on the group. On average, Post-Test was about 13 points higher than the Pre Test.

Below is a graph showing the relation between Pre Test and Post Test per participant. The red line shows $($ Pre Test $=$ Post Test $)$. 


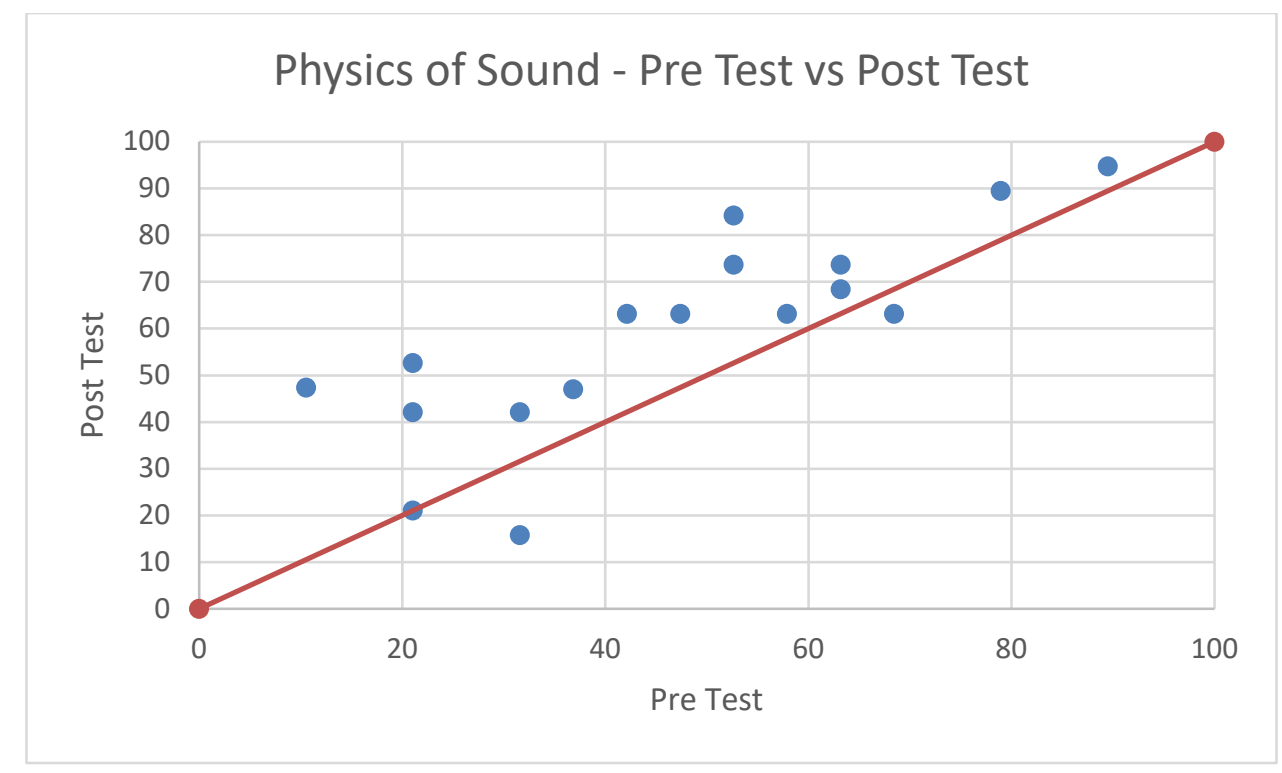

Figure 2. Physics of Sound and Mathematics of Music $(n=17)$ - Content Knowledge Pre-Test versus Post-Test. The line in the graph represents score Pre-Test $=$ score Post-Test

From the graph presented above, it is possible to see that the large majority (14 participants) of the participants that completed the Pre and Post-test $(n=17)$ shows a Post Test higher that the Pre-Test.

\subsubsection{3 - Introduction to Robotics}

Results of the paired-samples t-test show that mean of the knowledge test differs before the Professional Development (PD) $(\mathrm{M}=76.7, \mathrm{SD}=14)$ and after the $\mathrm{PD}(\mathrm{M}=81.5, \mathrm{SD}=12.2)$ at the .05 level of significance $(\mathrm{t}=2.997, \mathrm{df}=21, \mathrm{n}=22, \mathrm{p}=0.007<.05,95 \%)$ meaning that the intervention (PD) has a significant impact on the group. On average, Post-Test was about 4.8 points higher than the Pre Test.

Below is a graph showing the relation between the Pre-Test and Post-Test per participant. The red line shows $($ Pre-Test $=$ Post-Test). 


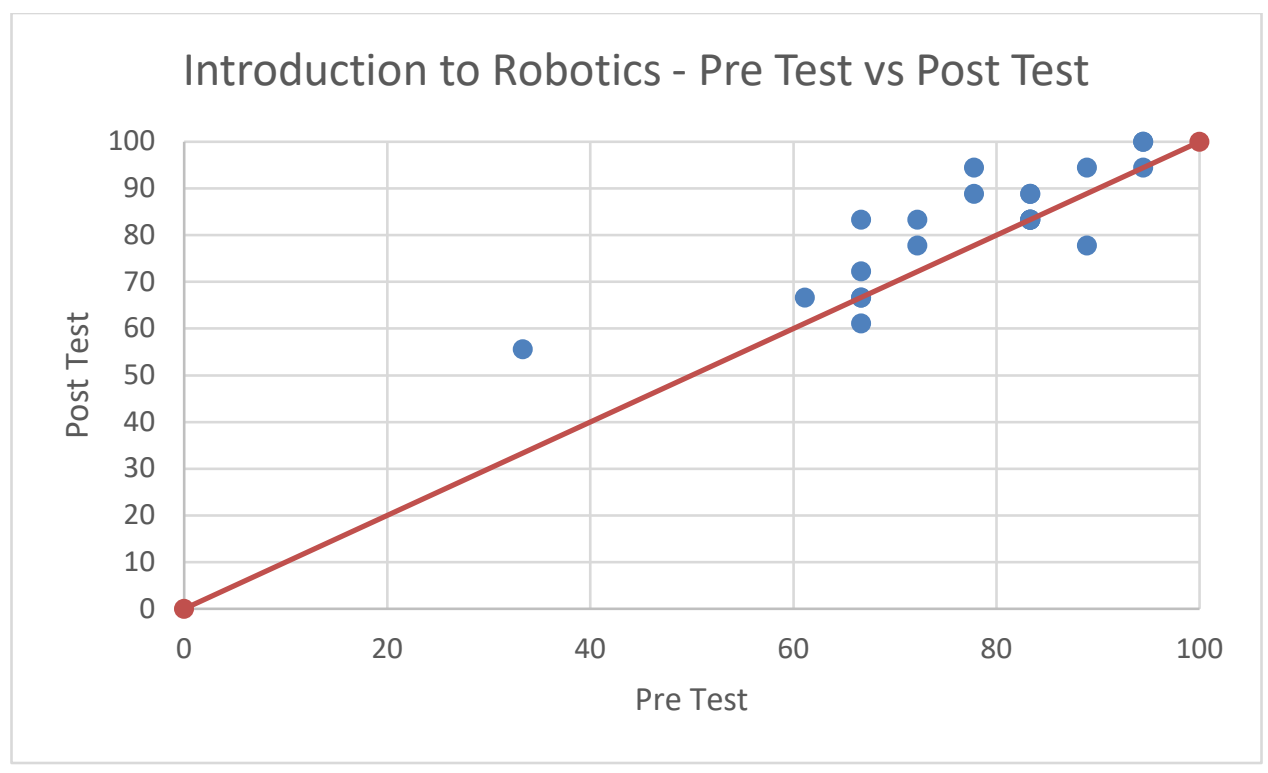

Figure 3. Introduction to Robotics ( $\mathrm{n}=22)$ - Content Knowledge Pre-Test versus Post-Test. The line in the graph represents score Pre-Test $=$ score Post-Test

From the graph presented above, it is possible to see that the majority ( 13 participants, $n=22$ ) shows a Post-Test higher that the Pre-Test.

Below are the statements of two instructors - Instructor A and Instructor B, after a brief telephone interview. They both work as staff of a CBO; neither of them had a STEM/STEAM background, and they participated in the PD series. They implemented the module Alternative Energies in their communities. The following are transcriptions of two of the questions.

1) Do you believe that the Professional Development provides you with enough content knowledge for you to feel confident when sharing this knowledge with the children in your community organization? What are the reasons for your answer?

Instructor A: Yes, "the PD instructor" does a phenomenal job explaining all content and giving instructors a variation of ways in which we can engage the children. If we have any questions, he is always willing to answer them and make sure that we know the material before sharing it with our participants.

Instructor B: Yes, I do believe the content knowledge shared at the PD is enough for me to take back and share with my youth at "my CBO." Taking written notes and being sure to label which records go with which lesson helps to share that content with the kids. It is also great to see and hear other instructors share their ideas on how they run their program.

2) Do you believe that the Professional Development provides you with enough hands-on experience for you to feel confident when sharing this knowledge with the children in your community organization? What are the reasons for your answer? 
Instructor A: Yes, this professional development has a lot of hands-on opportunities that allow the instructors to get the experience. We were able to practice the skills multiple times enough to feel confident when demonstrating it to the children.

Instructor B: Yes, being able to do the hands-on experience is more than enough to take back and share with the kids. Being able to do that at the PDs allows me to get my questions out of the way. I am also able to record how to do specific tasks, depending on what the PD module is. Being able to do the hands-on tasks in the PD allows me to learn what I will teach and see different techniques other instructors use to complete their module pieces.

To conclude, let's review the questions this paper wants to explore are:

1) Have the PDs implemented by Scientists for Tomorrow positively impacted module instructors' content knowledge and attitude toward STEAM-related subjects and careers?

2) Are these PDs promoting professionals outside of typical STEAM professions to become effective STEAM instructors?

Based on the data (qualitative and quantitative) presented above, there is evidence showing that the PD series has a positive impact on the potential instructors. The data also illustrate that:

1) The professional development series produced a positive environment to learn STEAM,

2) The attitude towards STEAM of the participants was positive from the starter, and this positive attitude reminds among the participants (increases but its change is not significative)

3) There is a significative gain in Content Knowledge on the three modules: Alternative Energies, The Physics of Sound and Mathematics of Music and Introduction to Robotics

4) Participants that completed the PD series are confident that the content knowledge and the pedagogical content knowledge will be useful when teaching the module in their sites

They stated that they feel prepared and confident to take the role assigned (or self-selected) as an OST academic enrichment instructor in the CBOs site implementing the STEM/STEAM modules. However, many of them are "not professionals" in the STEM/STEAM fields.

\section{5- Conclusion}

It is clear, after the investment from all the stakeholders (potential instructors, CBOs, and Columbia College Chicago, that it is possible to generate a path to provide qualified instructors to promote STEM/STEAM education in those neighborhoods where the access to this kind of knowledge is limited.

But, the idea behind the Professional Development series is more significant that prepare personal to participate as a practitioner in STEM/STEAM informal education in non-privileged neighborhoods. It is to generate a wave of local stakeholders that after gaining confidence in implementing STEM/STEAM programs, they will continue promoting these high-quality 
STEM/STEAM activities. With their support, this high-quality education path will become the new normal in these neighborhoods, and not just a temporary event.

It is time to promote transformational solutions and not meaningless patches. The content knowledge/skill gap between the youth from privileged and non-privileged is significant, and it is continually growing. In the time of the inception of the $4^{\text {th }}$ Industrial Revolution and the changes it brings to the labor market, it will be irresponsible not to procure ways to deliver highquality STEM/STEAM education for ALL.

Many scholars, between them Yuval Harari, are discussing in their work that humanity is changing fast, and with the change is generating a new social group: the group of "useless people." They define this group as individuals that lack the necessary skills to be productive members of society. Today individual with a lack of STEM/STEAM skills is running in a significant disadvantage when competing with those that mastering those skills. This phenomenon is happening today. The reader can see concrete examples of this phenomenon in Robotics competitions, Science Fair, and other similar events.

The author hopes that more potential instructors from the communities will join this process, and with them, a wave of change will prevail in these non-privileged neighborhoods.

\section{6 - Acknowledgments}

The author will like to thank all the Community Based Organization that invested their resources trying to promote STEM/STEAM in their communities. Also, the author will want to thanks the potential instructors that participate in the Professional Development series on long Saturdays, putting their needs aside for the good of their communities and to Columbia College Chicago for providing the opportunity, space, and resources to make this PD series a reality. 


\section{7 - References}

[1] National Science Board (NSB). (2010). Preparing the Next Generation of STEM Innovators: Identifying and Developing Our Nation's Human Capital. Arlington, VA: National Science Foundation. https://www.nsf.gov/nsb/publications/2010/nsb1033.pdf

[2] Prepare and Inspire: K-12 Education in Science, Technology, Engineering, and Math (STEM) Education for America's Future https://nsf.gov/attachments/117803/public/2a-Prepare and Inspire--PCAST.pdf.

[3] The U.S. Science and Engineering Workforce: Recent, Current, and Projected Employment, Wages, and Unemployment https://fas.org/sgp/crs/misc/R43061.pdf.

[4] U.S. Department of Education, “Secretary Arne Duncan's Remarks at OECD's Release of the Program for International Student Assessment (PISA) 2009 Results," press release, December 7, 2010, http://www.ed.gov/news/speeches/secretary-arne-duncans-remarks-oecds-releaseprogram-international-student-assessment;

[5] Brandon Wright, What do International Tests Really Show About U.S. Student Performance, Thomas B. Fordham Institute, January 24, 2013, http://www.edexcellence.net/commentary/education-gadfly-weekly/2013/january-24/what-dointernational-tests-reallyshow-about-us-performance.html

[6] U. S. Office of Science and Technology Policy / National Science and Technology Council. (2013). Federal Science, Technology, Engineering, and Mathematics 5-Years Strategic Plan Washington, DC: Author.

https://obamawhitehouse.archives.gov/sites/default/files/microsites/ostp/stem_stratplan_2013.pdf

[7] ACT Now (2014) Illinois Statewide Afterschool Quality Standards

[8] Grossman, J. B., Lind, C., Hayes, C., McMaken, J., \& Gersick, A. (2009). The cost of quality out-of-school-time programs. Philadelphia, PA: Public/Private Ventures.

[9] STEM ecosystems (2019, June 4) Retrieved from https://stemecosystems.org/

[10] Mulvaney Hoyer, K., Sparks, D. (2017). Instructional Time for Third-and Eighth-Graders in Public and Private Schools: School Year 2011-12 - National Center for Education Statistics. Retrieved from https://nces.ed.gov/pubsearch/pubsinfo.asp?pubid=2017076

[11] Traill, S. \& Traphagen, K., with Devaney, E. (2015) Assessing the Impacts of STEM Learning Ecosystems: Logic Model Template and Recommendations for Next Steps. Noyce Foundation. Retrieved from http://stemecosystems.org/wpcontent/uploads/2015/11/Assessing Impact Logic Model Template STEM Ecosystems Final. $\underline{\mathrm{pdf}}$ 
[12] Duncan, G. J., \& Murnane, R. J. (2014). Growing Income Inequality Threatens American Education. Phi Delta Kappan, 95(6), 8-14. https://doi.org/10.1177/003172171409500603

[13] Ganimian, A. J., \& Murnane, R. J. (2016). Improving Education in Developing Countries: Lessons From Rigorous Impact Evaluations. Review of Educational Research, 86(3), 719-755.

[14] Kraft, M. A., Blazar, D., \& Hogan, D. (2018). The Effect of Teacher Coaching on Instruction and Achievement: A Meta-Analysis of the Causal Evidence. Review of Educational Research, 88(4), 547-588. https://doi.org/10.3102/0034654318759268

[15] Duncan, G. J. \& Murnane, R. J. (2016). Rising Inequality in Family Incomes and Children's Educational Outcomes. RSF: The Russell Sage Foundation Journal of the Social Sciences 2(2), 142-158. Russell Sage Foundation. Retrieved June 10, 2019, from Project MUSE database.

[16] Ejiwale, J. (2013). Barriers to successful implementation of STEM education. Journal of Education and Learning. Vol.7 (2) pp. 63-74.

[17] Caplan, M. (2017, June), Scientists for Tomorrow - A Self-Sustained Initiative to Promote STEM in Out-of-School Time Frameworks in Under-served Community-Based Organizations: Evaluation and Lessons Learned Paper presented at 2017 ASEE Annual Conference \& Exposition, Columbus, Ohio. https://peer.asee.org/28812 